\title{
Evaluation of in situ and remote sensing sampling methods for SPM concentrations, Belgian continental shelf (southern North Sea)
}

\author{
Michael P. Fettweis • Bouchra Nechad
}

Received: 3 November 2009/Accepted: 15 June 2010 /Published online: 13 July 2010

(C) The Author(s) 2010. This article is published with open access at Springerlink.com

\begin{abstract}
Large sets of suspended particulate matter (SPM) concentration data from in situ and remote sensing (moderate resolution imaging spectroradiometer, MODIS) samplings in the Belgian nearshore area (southern North Sea) are combined in order to evaluate their heterogeneity and the sampling techniques. In situ SPM concentration measurements are from a vessel (tidal cycle) and from a tripod. During the tidal cycle measurements, vertical profiles of SPM concentration have been collected; these profiles have been used as a link between satellite surface and near-bed tripod SPM concentrations. In situ time series at fixed locations using a tripod are excellent witnesses of SPM concentrations under all weather conditions and may catch SPM concentration variability with a much finer scale. The heterogeneity has been statistically assessed by comparing the SPM concentration frequency distributions. Tidal cycle, tripod and MODIS datasets have different distributions and represent a different subpopulation of the whole SPM concentrations population. The differences between the datasets are related to meteorological conditions during the measurements; to near-bed SPM concentration dynamics, which are partially uncoupled from processes higher up in the water column; to the sampling methods or schemes and to measurement uncertainties. In order to explain the differences between the datasets, the tripod data have been subsampled using wave height conditions and satellite and tidal cycle sampling schemes.
\end{abstract}

Responsible Editor: Han Winterwerp

M. P. Fettweis $(\bowtie) \cdot$ B. Nechad

Management Unit of the North Sea Mathematical Models

(MUMM), Royal Belgian Institute of Natural Sciences,

Gulledelle 100,

1200 Brussels, Belgium

e-mail: m.fettweis@mumm.ac.be
It was found that satellites and low-frequent tidal cycle measurements are biased towards good weather condition or spring-summer seasons (satellite). The data show that the mean surface SPM concentration derived from satellite data is slightly lower than from in situ tidal cycle measurements, whereas it is significantly lower than the mean SPM concentration interpolated to the water surface from the tripod measurements. This is explained by the errors arising from the interpolation along the vertical profiles, but also by the fact that satellite-measured signal saturates in the visible band used to retrieve SPM concentration in very turbid waters.

Keywords SPM concentration · MODIS · In situ measurements $\cdot$ Sampling methods $\cdot$ Sampling scheme

\section{Introduction}

The dynamics of suspended particulate matter (SPM) control processes such as sediment transport, deposition, resuspension, primary production and the functioning of benthic communities. Improving our understanding of SPM concentration variability in nearshore areas, where the SPM concentration is particularly high, is essential to assess the human footprint on this environment and to develop sustainable socioeconomic activities in parallel with marine environmental protection. SPM concentration varies strongly in the Belgian coastal area depending on seasons, tides and random events such as storms, which points out the need for optimal sampling strategies in order to assess this variability.

Short-term variations (tides) can be assessed using in situ or remote sensing (RS) sampling techniques. In situ SPM concentration measurements are carried out from a vessel 
and using stand-alone structures such as tripods or measuring piles. Automated tripods, measuring piles, smartbuoys or other platforms allow recording continuous time series of SPM concentration at specific sites for prolonged periods of time and during extreme events (storms; see, e.g. Cacchione et al. 1995; Li et al. 1997; Blewett and Huntley 1998; Ogston et al. 2000; Pepper and Stone 2004; Ma et al. 2008; Badewien et al. 2009). Ships of opportunity with ferry boxes allow also collecting over more extended periods and are not limited to one location (Buijsman and Ridderinkhof 2007). They usually sample only the near-surface and have a lower time resolution than fixed platforms. Measurements from research vessels often cover limited periods and sea states, but allow measuring vertical SPM concentration profiles. During tidal cycle measurements, water samples can be collected for calibration of optical backscatter sensors (OBS) or transmissometer. Large synoptic scenes of surface SPM concentrations may be retrieved from satellites (Bowers et al. 2002; Nechad et al. 2003; Zawada et al. 2007; Eleveld et al. 2008; Doxaran et al. 2009). For the southern North Sea, 40-85 pictures are available per year (on average 63 images for 2003-2008) having a cloud cover $<50 \%$ over water.

Time series of in situ SPM concentration and satellite imagery are valuable data sources for the analysis of suspended sediment transport in coastal or estuarine areas (Ruhl et al. 2001; Fettweis et al. 2007). Still, shortcomings remain, with satellite imagery suffering from a low temporal resolution relative to tidal cycle or (semi-) permanent stations and only related to surface data, whilst in situ measurements have a limited spatial resolution.

Ship time and budget are often limited; it is thus of primary importance to choose a sampling method or a combination of methods providing a representative subsample of the population in the time and space domain. If long-term variations induced by natural changes or anthropogenic effects need resolving, then overprinting tidal, weather, neap-spring and also seasonal signals need filtering. This requires sufficiently dense sampling in time and long data series. To our knowledge, only few efforts are being made to design or evaluate existing sampling schemes (Bograd et al. 1999; Shindo and Otsuki 1999; Caeiro et al. 2003; Hall and Davies 2005; Werdell et al. 2009). Often, the best sampling strategy cannot be applied as it depends often on a compromise between costs and benefits. In practice, a mixture of objectives is achieved following an adapted suboptimal strategy. Autonomous stations (tripods) with an almost continuous measurement of SPM concentration are relatively easy to design; still, they do not cover large areas. Satellite cover large-scale scenes, but at lower time resolution and with gaps in data often occurring during stormy weather conditions, though missing high ranges of SPM concentrations often occur during these phases. Very high SPM concentrations may also be missed by satellites due to saturation in the visible bands used to retrieve SPM concentration (Bowers et al. 1998; Doxaran et al. 2002; Nechad et al. 2010). Knowledge on the uncertainty introduced by the sampling method and instrumentation is therefore important in data interpretation, as well as data assimilation. Indeed, central to the concept of data assimilation is error estimation associated with model output and observations (Lynch et al. 2009; Stow et al. 2009).

The aim of this paper was to evaluate the temporal SPM heterogeneity in the Belgian nearshore using a large set of SPM concentration data from moderate resolution imaging spectroradiometer (MODIS) ocean colour satellite and from in situ measurements (both tidal cycle and semi-permanent tripod) to determine the statistical characterisation of these datasets and to examine how they describe the nature of coastal systems. As matchups (satellite picture at the same time as in situ measurements) are scarce, statistical methods are used to evaluate the differences and similarities in the datasets. This approach is new and allows comparing different datasets not necessarily sampled at the same moment in time.

\section{Region of interest}

The study area is situated in the southern North Sea (Fig. 1). Water depths vary between 0 and $20 \mathrm{~m}$ below mean lowest low water spring (MLLWS). Tides are semidiurnal with a mean tidal range at Zeebrugge of $4.3 \mathrm{~m}$ at spring and $2.8 \mathrm{~m}$ at neap tide. The tidal current ellipses are elongated in the nearshore area and become gradually more semi-circular further offshore. Maximum current velocities are higher and minima lower in the nearshore area than further offshore. The current velocities near Zeebrugge (nearshore) vary from 0.2 to $1.5 \mathrm{~m} \mathrm{~s}^{-1}$ during spring tide and from 0.2 to $0.6 \mathrm{~m} \mathrm{~s}^{-1}$ during neap tide and more offshore between 0.2 and $0.6 \mathrm{~m} \mathrm{~s}^{-1}$ during spring tide and between 0.1 and $0.3 \mathrm{~m} \mathrm{~s}^{-1}$ during neap tide (see operational model results at www.mumm.ac.be). Winds blow predominantly from the southwest and the highest waves occur during northwesterly winds. SPM forms a turbidity maximum between Oostende and the mouth of the Westerschelde (Fig. 1). The strong tidal currents and the low freshwater discharge of the Schelde (yearly average is $100 \mathrm{~m}^{3} \mathrm{~s}^{-1}$ ) result in a well-mixed water column with very small salinity and temperature stratification. Measurements indicate variations in SPM concentration in the nearshore area of $20-70 \mathrm{mg} \mathrm{l}^{-1}$ and reaching 100 to $>3,000 \mathrm{mg} \mathrm{l}^{-1}$ near the bed; lower values $\left(<10 \mathrm{mg}^{-1}\right)$ occur offshore (Fettweis et al. 2010). The most important sources of SPM are the French rivers discharging into the English Channel, 
Fig. 1 Map of the southern North Sea with the in situ SPM concentration measurement stations MOW1 and Kwintebank. The background consists of the yearly averaged surface SPM concentration $\left(\mathrm{mg} \mathrm{l}^{-1}\right)$ in the southern North Sea, from MODIS images (2003-2008)

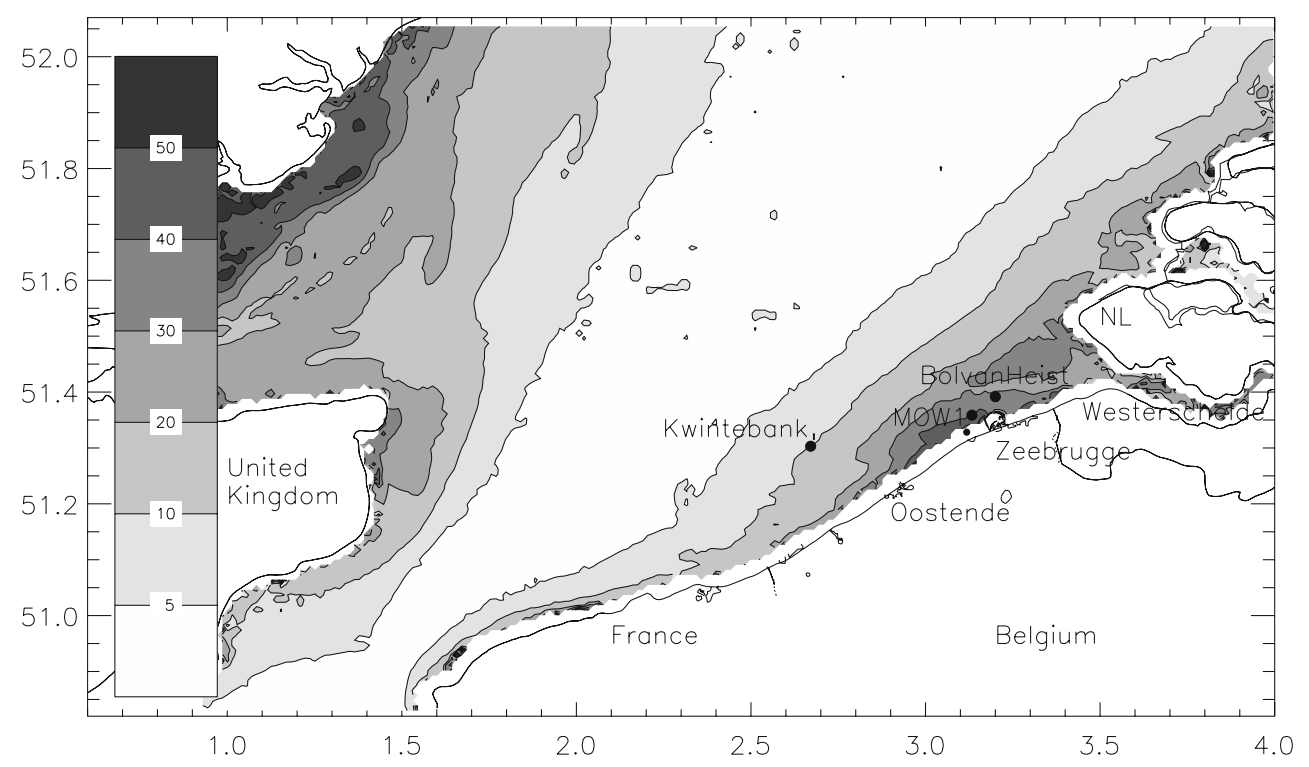

coastal erosion of the Cretaceous cliffs at Cap Griz-Nez and Cap Blanc-Nez (France) and the erosion of nearshore Holocene mud deposits (Fettweis et al. 2007).

In situ measurements are available at two locations in the Belgian coastal area (MOW1, Kwintebank; see Tables 1 and 2): MOW1 $\left(51^{\circ} 21.63^{\prime} \mathrm{N}, 3^{\circ} 7.41^{\prime} \mathrm{E}\right)$ is located in the turbidity maximum zone (water depth about $10 \mathrm{~m}$ MLLWS), whereas the Kwintebank $\left(51^{\circ} 18.03^{\prime} \mathrm{N}, 2^{\circ} 40.20^{\prime} \mathrm{E}\right)$ is more offshore (water depth about $20 \mathrm{~m}$ MLLWS) and situated at the edge of the high turbidity zone (Fig. 1). Holocene medium-consolidated mud characterises the seabed at the MOW1 site, albeit covered with an ephemeral slightly muddy fine sand layer with a median grain size of about $170 \mu \mathrm{m}$. The Kwintebank site is a sandy environment with a median grain size of $>250 \mu \mathrm{m}$; mud content is very low $(<2 \%)$.

\section{Materials and methods}

SPM concentration data have been obtained using OBSs, deployed from a vessel and an autonomous tripod, and from the MODIS satellite. To compare surface satellite data with near-bed tripod data both, the satellite images have to be corrected towards near-bed values or the tripod data towards the surface. This has been done on the basis of tidal cycle measurements during which vertical profiles of SPM concentrations were recorded. Significant wave height at a coastal station (Bol van Heist, see Fig. 1) for the period 2003-2008 have been used to characterise meteorological and sea state conditions.

\subsection{In situ tripod measurements}

The tripod was developed for collecting time series (up to 50 days) of SPM concentration and current velocity at fixed locations. A SonTek 3-MHz Acoustic Doppler Profiler, a SonTek 5-MHz Acoustic Doppler Velocimeter Ocean, a Sea-Bird SBE37 CT system and two OBS sensors (one at about 0.2 and the other at about $2 \mathrm{~m}$ above bottom, hereafter referred to as mab) were mounted on the frame. Only the OBSs are discussed here as unpredictable dynamics of the natural system still limits the accuracy of conversions of acoustic backscatter data into SPM concen-
Table 1 Tripod measurements at MOW1 and on the Kwintebank

\begin{tabular}{lllc}
\hline Location & Start date and time & End date and time & Duration (days) \\
\hline Kwintebank & $02 / 03 / 200415: 10$ & $11 / 03 / 200409: 40$ & 8.83 \\
MOW1-1 & $18 / 10 / 200412: 12$ & $08 / 11 / 200411: 10$ & 20.92 \\
MOW1-2 & $08 / 02 / 200508: 10$ & $18 / 02 / 200510: 00$ & 10.08 \\
MOW1-3 & $04 / 04 / 200511: 10$ & $15 / 04 / 200507: 24$ & 10.83 \\
MOW1-4 & $22 / 06 / 200508: 15$ & $11 / 07 / 200511: 35$ & 19.13 \\
MOW1-5 & $22 / 11 / 200508: 27$ & $05 / 12 / 200509: 07$ & 13.04 \\
MOW1-6 & $13 / 02 / 200611: 25$ & $27 / 02 / 200610: 28$ & 13.96 \\
MOW1-7 & $27 / 03 / 200610: 36$ & $18 / 04 / 200609: 26$ & 19.08 \\
MOW1-8 & $15 / 05 / 200612: 24$ & $15 / 06 / 200610: 22$ & 30.96 \\
\hline
\end{tabular}


Table 2 Tidal cycle measurements at MOW1and on the Kwintebank
$M T$ mean tide, $N T$ neap tide, $S T$ spring tide

\begin{tabular}{|c|c|c|c|c|}
\hline ID no. & Location & Start date and time & End date and time & Tide \\
\hline 2001/06-A & MOW1 & 07/03/2001 16:11 & 08/03/2001 09:38 & MT \\
\hline 2002/27-B & MOW1 & $26 / 11 / 200218: 34$ & 27/11/2002 07:24 & NT \\
\hline 2003/04-A & MOW1 & 19/02/2003 18:08 & 20/02/2003 05:01 & ST \\
\hline $2003 / 15$ & Kwintebank & 11/06/2003 18:20 & 12/06/2003 07:00 & MT \\
\hline $2003 / 17$ & Kwintebank & $26 / 06 / 2003 \quad 16: 40$ & 27/06/2003 05:00 & NT \\
\hline $2003 / 22$ & MOW1 & 08/09/2003 18:00 & 09/09/2003 08:00 & MT \\
\hline $2003 / 25$ & Kwintebank & 09/10/2003 15:30 & 10/10/2003 04:20 & ST \\
\hline $2004 / 04$ & Kwintebank & 02/03/2004 20:00 & 03/03/2004 08:40 & NT \\
\hline $2004 / 05$ & Kwintebank & 11/03/2004 18:00 & 12/03/2004 07:10 & ST \\
\hline $2004 / 24$ & MOW1 & 18/10/2004 13:20 & 19/10/2004 02:20 & ST \\
\hline 2004/25-A & MOW1 & 08/11/2004 18:20 & 09/11/2004 07:00 & NT \\
\hline $2005 / 02$ & MOW1 & 07/02/2005 14:00 & 08/02/2005 06:10 & MT \\
\hline 2005/07-A & MOW1 & 04/04/2005 19:20 & 05/04/2005 08:20 & NT \\
\hline 2005/15-A & Kwintebank & 20/06/2005 20:20 & 21/06/2005 09:00 & MT \\
\hline 2005/15-B & MOW1 & $21 / 06 / 2005 \quad 17: 15$ & $22 / 06 / 200506: 10$ & MT \\
\hline $2005 / 29$ & MOW1 & 21/11/2005 17:00 & $22 / 11 / 200506: 00$ & NT \\
\hline $2006 / 06$ & MOW1 & $28 / 03 / 200618: 38$ & 28/03/2006 06:00 & ST \\
\hline 2006/10-A & MOW1 & $15 / 05 / 2006 \quad 17: 28$ & $16 / 05 / 200606: 20$ & ST \\
\hline 2007/11-A & Kwintebank & 02/05/2007 14:38 & 03/05/2007 03:00 & MT \\
\hline 2007/11-B & MOW1 & 03/05/2007 06:43 & 03/05/2007 20:00 & MT \\
\hline $2007 / 16$ & MOW1 & 10/07/2007 04:30 & 10/07/2007 17:00 & NT \\
\hline $2007 / 25-B$ & MOW1 & 23/10/2007 01:30 & 23/10/2007 12:00 & MT \\
\hline 2008/02-A & MOW1 & 06/02/2008 11:00 & 07/02/2008 01:00 & ST \\
\hline 2008/02-B & Kwintebank & 07/02/2008 17:00 & 08/02/2008 06:00 & ST \\
\hline
\end{tabular}

trations (Hoitink and Hoekstra 2005; Bartholomä et al. 2009). The OBSs have been calibrated using linear regression lines obtained from tidal cycle measurements carried out during the same period. During the period 2003-2006, 147 days of data have been collected at both locations, from which 9 days on the Kwintebank and 138 at MOW1 (Table 1 and Fig. 2). Respectively 33\%, 20\%, 22\% and $25 \%$ of the data at MOW1 have been collected during spring, summer, autumn and winter seasons. The Kwintebank data are all collected during winter. The sampling frequency was 2 min on the Kwintebank and varied between 2 min up to
$20 \mathrm{~min}$ at MOW1. For analysis purpose, a frequency of 20 min was used at MOW1, giving in total about 10,000 sampling events at MOW1.

3.2 In situ tidal cycle measurements and vertical profiles

During the period 2001-2008, 16 tidal cycle measurements have been carried out at MOW1 and eight on the Kwintebank (Table 2 and Fig. 2). During the measurements, the ship remained anchored during one tidal cycle (about 13 h). The Sea-Bird SBE09 SCTD carousel

\section{- | I | | | I | I}

$\triangle$

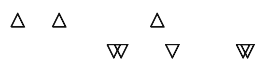

$\triangle \Delta \Delta \underset{\substack{\nabla \\ \Delta}}{\Delta} \Delta \quad \Delta \Delta$ $\begin{array}{lll}\triangle & \Delta \quad \Delta & \Delta \\ \nabla & \nabla\end{array}$

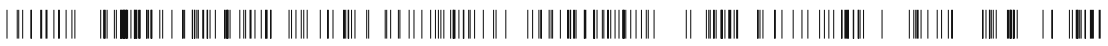

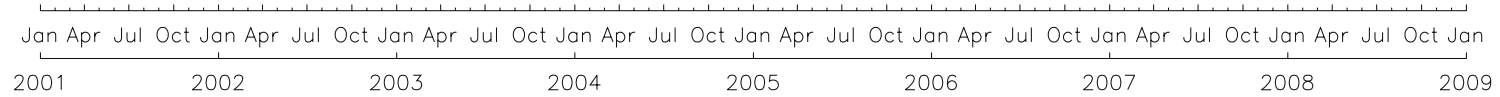

Fig. 2 The nine tripod deployment (solid lines, first deployment is at Kwintebank, the others at MOW1), 24 tidal cycle measurements (upward triangle: MOW1, downward triangle: Kwintebank) and 460 MODIS cloud-free images (vertical lines) are shown on a time axis covering the period 2001-2008 (see Tables 1 and 2). Tidal cycle measurement lasts $13 \mathrm{~h}$ and the tripod deployments between 9 and 31 days 
sampling system, containing twelve 10-1 Niskin bottles and an OBS was kept at about $3 \mathrm{~m}$ above bottom (mab). Every 20 min, a Niskin bottle was closed and every hour the carousel was taken on board the vessel. At every sampling occasion, three subsamples were taken and filtered on board using pre-weighted GF/C filters. These samples were later dried and weighted to obtain SPM concentrations, which were linearly correlated to OBS measurements in view of calibrating the OBS. The uncertainties due to filtration are relatively higher in clearer waters due to a relatively higher systematic error (Fettweis 2008). There are 12\% and 60\% of relative standard deviation in all tidal cycle measurements that include a systematic error of $4.5 \mathrm{mg}^{-1}$, respectively taken at the MOW1 and the Kwintebank locations. The relative standard deviation in the SPM concentration derived from OBS, taking into account the uncertainties of the filtration, is $<20 \%$ (on average $10 \%$ for all tidal cycles) at MOW1 and up to $56 \%$ (on average $23 \%$ for all tidal cycles) at the Kwintebank.

Per retrieval of the carousel, a vertical profile was measured. About 13 profiles per tidal cycle have thus been collected. In total, 198 vertical profiles are available at MOW1 and 103 on the Kwintebank. Tidal cycle measurements are well distributed over neap, mean and spring tide and seasons. Respectively $25 \%, 19 \%, 31 \%$ and $25 \%$ of the data at MOW1 have been collected during spring, summer, autumn and winter seasons and 31\%,38\% and 31\% during neap, mean and spring tide. For the Kwintebank data, the distribution over the seasons is as follows: $37 \%$ spring, $13 \%$ summer, $13 \%$ autumn and $37 \%$ winter; over lunar phases: $25 \%$ neap tide, $37 \%$ mean tide $37 \%$ spring tide.

The measured vertical profiles cover the water column from 3 mab towards the surface. Therefore, a linear regression (minimising absolute deviation) between water depth and the logarithm of the SPM concentration, averaged over depths cells of $0.5 \mathrm{~m}$, was calculated to construct the missing lower part of the profiles. The fitted profiles have been used to calculate ratios between SPM concentration at the surface and at different depths in order to extrapolate surface SPM concentration, measured by the satellite towards deeper water layers and/or near-bed SPM concentration, measured by the tripod towards the surface (Van den Eynde et al. 2007).

\subsection{Remote sensing data}

MODIS data of level 1A (L1A), covering the period 20032008, have been downloaded from the NASA GSFC web site http://oceancolor.gsfc.nasa.gov. The L1A data contain the radiance at the top of the atmosphere, which were geometrically corrected using the SeaDAS software (available from the same NASA web site). The turbid water atmospheric correction (Ruddick et al. 2000) implemented in SeaDAS was then applied to obtain the marine (waterleaving) reflectance.

SPM concentrations were derived from water-leaving reflectance following an algorithm calibrated for turbid waters (Nechad et al. 2010). The accuracy of satellitederived SPM concentration has been assessed for errors that may arise from the optical model used to convert marine reflectances to SPM concentrations. The model parameterises the inherent optical properties of particles in suspension as site-averaged coefficients. This induces errors in SPM estimation when a significant change in particles size and composition occurs under tidal and wind effect (Nechad et al. 2010), changing significantly their inherent optical properties. The uncertainty in SPM concentration propagating from errors in the water-leaving reflectance retrieval has been evaluated on the basis of 29 matchups taken in clear to moderately turbid waters $\left(3-80 \mathrm{mg} \mathrm{l}^{-1}\right)$. A bulk mean relative error about $37 \%$ has been found in SPM concentration retrieval from MODIS imagery. For waters with SPM concentration $>10 \mathrm{mg} \mathrm{l}^{-1}$, the relative errors in MODIS-derived SPM concentration are significantly lower than in clearer waters. This comes from the fact that there are higher relative errors in water-leaving reflectance retrieved in clearer waters and also because the SPM concentration algorithm is adapted to turbid waters. Besides, satellite-visible bands usually saturate in very turbid waters (Doxaran et al. 2002). The band centred at wavelength $667 \mathrm{~nm}$ used here in the retrieval of SPM concentration following Nechad et al. (2010) reaches its limit of detection around $200 \mathrm{mg} \mathrm{l^{-1 }}$. The use of bands at longer wavelengths is recommended to overcome such limitations, provided these bands are not subject to high sensor noise ratio (Wang et al. 2009) or to high atmospheric correction-related errors.

For Belgian waters, about 60 (partially) cloud-free images per year are available from each sensor, resulting in total in 460 samples at MOW1 and 502 at the Kwintebank location. Sixty-four per cent of satellite images are during spring and summer and only $36 \%$ during autumn and winter. The latter two seasons are characterised by higher SPM concentrations.

MODIS satellite overpasses are between 12:40 and 13:40 UTC. In situ measurements falling within $1 \mathrm{~h}$ of satellite overpass (also called matchups) are averaged and compared with satellite data. The relative standard deviation of in situ data within $1 \mathrm{~h}$ during these matchups is on average $27 \%$. Seaborne and tripod measurements collected during satellite overpasses are averaged for each measurement station $1 \mathrm{~h}$ around the satellite time of overpass. The variability in time of the seaborne and tripod measurements is compared with the variability of the long-term RS data at each station to evaluate the possible agreement between different datasets. 


\section{Results}

\subsection{Significant wave height}

The median significant wave height $\left(H_{\mathrm{s}}\right)$ during the period $2003-2008$ is $0.55 \mathrm{~m}$. Lower values occur in spring $(0.48 \mathrm{~m})$ and summer $(0.53 \mathrm{~m})$ and higher ones in autumn $(0.62 \mathrm{~m})$ and winter $(0.60 \mathrm{~m})$. The median $H_{\mathrm{s}}$ during the tripod measurements at MOW1 was $0.58 \mathrm{~m}$ and at the Kwintebank $0.47 \mathrm{~m}$. The median during MOW1 measurements is thus slightly higher than the median over 20032008 , but significant wave heights $>1.5 \mathrm{~m}$ have occurred less frequently (7\% in MOW1 tripod data compared to $10 \%$ during the period 2003-2008).

During tidal cycle measurements, the median $H_{\mathrm{s}}$ was $0.49 \mathrm{~m}$; these measurements are limited to rather good weather, with $H_{\mathrm{s}}$ not exceeding $1.5 \mathrm{~m}$. The median $H_{\mathrm{s}}$ during satellite overpass in clouded weather is $0.60 \mathrm{~m}$. During a clear sky condition, when SPM concentration data are available from MODIS, the median reduces to $0.44 \mathrm{~m}$. This indicates that satellite SPM concentration data are biased towards good weather conditions (i.e. low wave condition) and that a significant wave height smaller than $0.44 \mathrm{~m}$ can be used as proxy for cloud-free conditions.

\subsection{Vertical profiles}

Some examples of measured and fitted profiles from tidal cycle measurements are shown in Fig. 3. Two types can be distinguished, which can both be approximated by a logarithmic function. The first one consists of well-mixed profiles with small vertical stratification (the vertical averaged to SPM concentration ratio is smaller than 2)

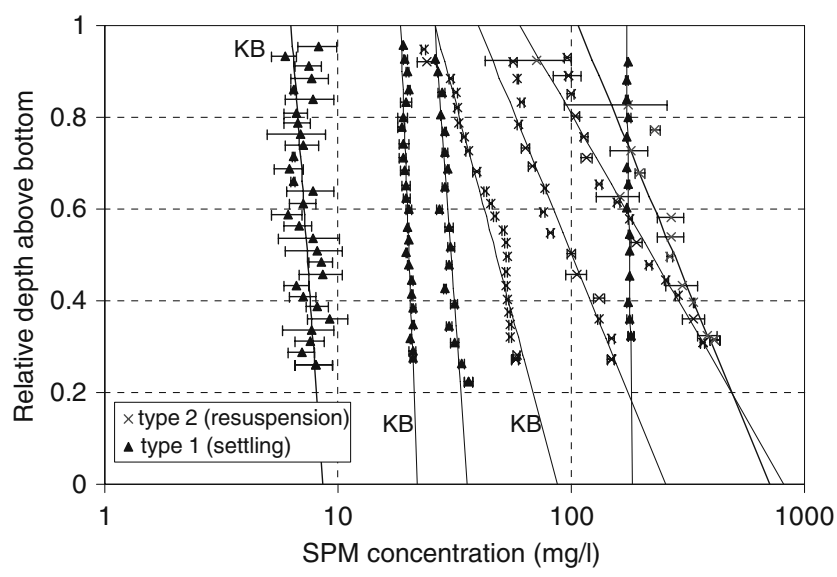

Fig. 3 Some examples of measured and fitted SPM concentration profiles from tidal cycle measurements. The measurements have been averaged over depth cells of $0.5 \mathrm{~m}$. Error bars are the standard deviation of this averaging. Depth is relative to total water depth. $K B$ Kwintebank; the other profiles are from MOW1 and the second one is characterised by strong vertical gradient (the vertical averaged to surface SPM concentration is $>2$ ). The latter type of profile is typically occurring around high and low water (Fig. 4), when the increasing current velocity has reached a critical value for resuspending the fluffy layer. Maximum current velocity occurs at about $1 \mathrm{~h}$ before high and low water. The first type of profile occurs when bed erosion flux is low because no erodable material is left on the bottom or because bed shear stress drops below a critical value for erosion. It thus reflects periods of vertical mixing or relaxation phases during slack waters. In the offshore location (Kwintebank) and at MOW1, 88\% and 74\%, respectively, of the profiles fit this type. The correlation coefficient between the fitted and the measured data is high at both locations (MOW1: $R^{2}=0.77$; Kwintebank: $R^{2}=0.98$ ).

The fitted profiles have been used to calculate a correlation between the log-transformed SPM concentration at the surface, at 2 and 0.2 mab and vertically averaged (Fig. 5 and Table 3). The correlations are large for type 1 profiles at both locations and type 2 profiles at the Kwintebank $\left(R^{2}>0.8\right)$, but weaker for type 2 profiles at MOW1 $\left(R^{2}=0.4-0.6\right)$. The lowest correlation occurs with the near-bed data $(0.2 \mathrm{mab})$, indicating that the extrapolation of near-bed values towards the surface is probably not accurate especially for the type 2 profiles.

A third type of profiles in the near-bed layer $(<2 \mathrm{mab})$ has been observed in the tripod data. It is characterised by very high SPM concentration in the near bed layer, which is possibly the result of the formation of ephemeral fluid mud layers or high concentrated benthic suspension (HCBS) layers, resulting in a weak correlation between the near bed and the 2 mab SPM concentration. They are typically associated with storm conditions (Fettweis et al. 2010). These HCBS layers cannot be fitted with the above profiles since near bed and water dynamics is uncoupled under these conditions.

The relation between the tidal averaged data at 2 and 0.2 mab has been calculated after log transformation of the data (see Fig. 6). For SPM concentrations ranging from 100 to $1,000 \mathrm{mg} \mathrm{l}^{-1}$, the near the bed concentration is $1.5-1.7$ times higher than at $2 \mathrm{mab}\left(R^{2}=0.69\right)$. Note that from the same range and during two time series (MOW1-4 and MOW1-8), near-bed SPM concentrations were 1.4-5.6 times higher than the SPM concentration at $2 \mathrm{mab}$. The correlation coefficient for these series is low $\left(R^{2}=0.33\right)$.

\subsection{Matchups between in situ and satellite data}

Nineteen matchups between satellite and tripod data are available during the period 2004-2006 at MOW1. The correlation - after log transformation of the data-between 

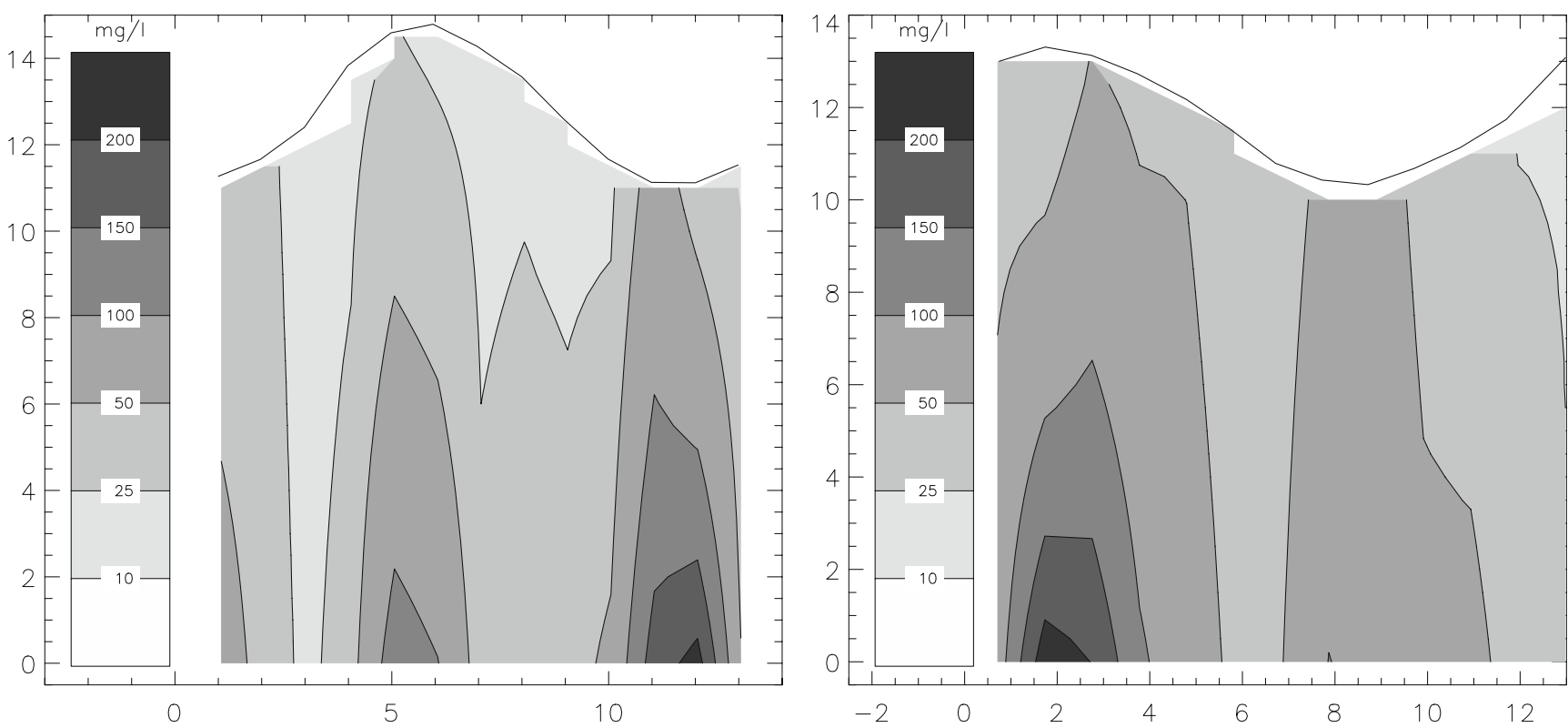

Fig. 4 SPM concentration profiles from fitted data during two tidal cycles at MOW1 (2003-22 and 2005-07). The y-axis represents depth above bed $(\mathrm{m})$ and the $x$-axis time $(\mathrm{h})$

surface SPM concentration from MODIS and near-bed SPM concentration has a coefficient of $R^{2}=0.8$ for the $2 \mathrm{mab}$ and $R^{2}=0.7$ for the 0.2 -mab data. Remark that the difference between the surface and near-bed SPM concentrations is huge (15-30 times lower; see Fig. 7a). Based on the relation between the surface and near-bed SPM concentration derived from the fitted profiles (obtained from the tidal cycle measurements), a depth correction of the MODIS surface data has been applied. When the correction factors for all profiles are considered (Table 3), then a relatively good match $\left(R^{2}=0.5\right)$ between MODIS and 2-mab tripod data is obtained (Fig. 7b), with an underestimation of the MODIS corrected data (see Section 5).

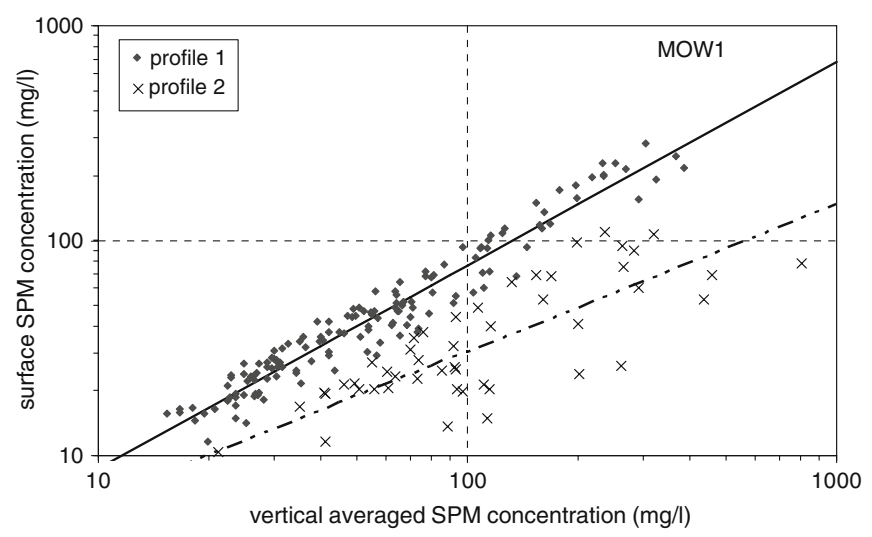

Fig. 5 Relation between surface SPM concentration and the vertical averaged SPM concentration for type 1 and type 2 profiles derived from the fitted profiles from tidal cycle measurements at MOW1 and

\subsection{Frequency distribution of SPM concentrations}

By using frequency distributions of different datasets, we can determine if two distributions are drawn from the same distribution function by use of standard statistic tests $\left(X^{2}\right.$ test, Kolmogorov-Smirnov test). If the data collected with different sampling methods have similar log-normal distributions, means and standard deviations, then we could conclude that-within the range of uncertainties - the methods provide similar subsamples from the whole population. From the three different types of SPM concentration data (tidal cycle, long term and satellite), probability distributions have been constructed (Figs. 8, 9

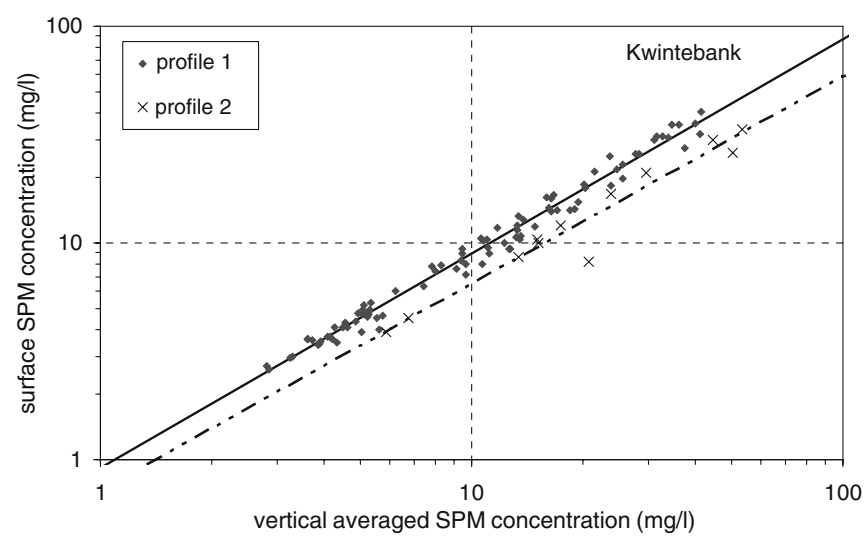

Kwintebank. The correlations are calculated after log transformation of the data (profiles 1: $R^{2}=0.94$, profiles $2: R^{2}=0.61$; see Table 3 ) 
Table 3 Linear correlation between the log-transformed data of surface SPM concentration $(x)$ and SPM concentration averaged over the water column at 2 and at $0.2 \mathrm{mab}(y)$

\begin{tabular}{|c|c|c|c|c|c|c|}
\hline & \multicolumn{3}{|l|}{ MOW1 } & \multicolumn{3}{|c|}{ Kwintebank } \\
\hline & vert avg & $2 \mathrm{mab}$ & $0.2 \mathrm{mab}$ & vert avg & $2 \mathrm{mab}$ & $0.2 \mathrm{mab}$ \\
\hline \multirow[t]{3}{*}{ Type 1 profiles } & $a=-0.01$ & $a=0.05$ & $a=0.10$ & $a=-0.04$ & $a=-0.05$ & $a=-0.04$ \\
\hline & $b=0.95$ & $b=0.89$ & $b=0.84$ & $b=0.99$ & $b=0.96$ & $b=0.95$ \\
\hline & $R^{2}=0.94$ & $R^{2}=0.88$ & $R^{2}=0.83$ & $R^{2}=0.98$ & $R^{2}=0.96$ & $R^{2}=0.95$ \\
\hline \multirow[t]{3}{*}{ Type 2 profiles } & $a=0.11$ & $a=0.27$ & $a=0.45$ & $a=-0.14$ & $a=-0.18$ & $a=-0.18$ \\
\hline & $b=0.69$ & $b=0.55$ & $b=0.45$ & $b=0.95$ & $b=0.89$ & $b=0.87$ \\
\hline & $R^{2}=0.63$ & $R^{2}=0.47$ & $R^{2}=0.38$ & $R^{2}=0.94$ & $R^{2}=0.89$ & $R^{2}=0.86$ \\
\hline \multirow[t]{3}{*}{ All profiles } & $a=0.30$ & $a=0.54$ & $a=0.73$ & $a=-0.01$ & $a=-0.01$ & $a=0.02$ \\
\hline & $b=0.72$ & $b=0.56$ & $b=0.44$ & $b=0.95$ & $b=0.88$ & $b=0.86$ \\
\hline & $R^{2}=0.63$ & $R^{2}=0.46$ & $R^{2}=0.35$ & $R^{2}=0.96$ & $R^{2}=0.91$ & $R^{2}=0.89$ \\
\hline
\end{tabular}

and 10). The data could be fitted with log-normal distributions. The distributions from the tidal cycle data are set for three depths, corresponding to the measuring depth of satellite (surface) and tripod data ( 2 and $0.2 \mathrm{mab}$ ). The probability of the $X^{2}$ test was computed, hypothesising that the SPM concentration data fit a log-normal distribution. The geometric mean ( $x^{*}$, further called mean) and multiplicative standard deviation $\left(s^{*}\right)$ of these distributions, together with the $X^{2}$ test results, are shown in Table 4. In general, values of $s^{*}$ vary between 1.5 and 2.8 ; hence, they fall within the most frequent range of approximately 1.4-3, observed in various branches of natural sciences (Limpert et al. 2001). If the test probability is low $(p<0.05)$, then the null hypothesis should be rejected. Low probability occurs only in the tidal cycle surface data at Kwintebank and the $0.2-\mathrm{mab}$ data at MOW1. The deviations from the lognormal distribution (Fig. 9) for the surface samples from the Kwintebank are possibly due to some high errors in SPM concentration (see Section 3). For the near-bed data at
MOW1, such deviations are related to some unrealistic high values obtained from $\log$ extrapolation of the vertical profiles from tidal cycle measurements to $0.2 \mathrm{mab}$. We can therefore argue that a type I error has occurred in these two populations and that SPM concentrations also have a log-normal distribution in these cases.

MOW1 is situated in shallow waters where wave effects are important. Excluding samples from the tripod measurements where the bottom wave orbital velocity, $U_{\mathrm{w}}$, is higher (respectively lower) than a certain value allows calculating the geometric mean and multiplicative standard deviation of a population representing stormy (respectively good) weather conditions (Table 5). The bottom wave orbital velocity has been calculated based on the significant wave height $\left(H_{\mathrm{s}}\right)$, the water depth and the JONSWAP spectrum of waves (Soulsby 1997). A $U_{w}$ of $0.03,0.3$ and $0.5 \mathrm{~m} \mathrm{~s}^{-1}$ correspond to a significant wave height of about $0.5,1.5$ and $2.5 \mathrm{~m}$ in a water depth of $10 \mathrm{~m}$. The results at MOW1 show that the distributions are

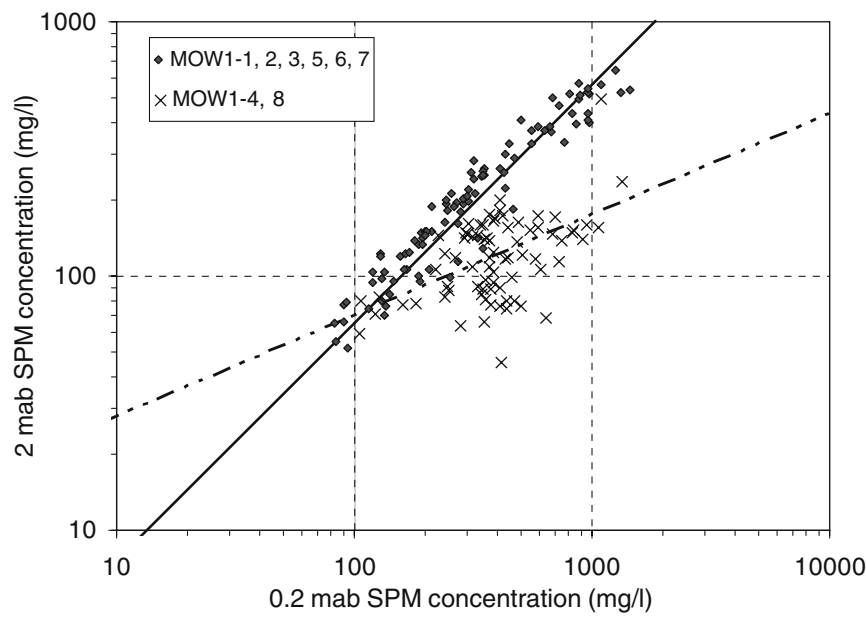

Fig. 6 Relation between tidal averaged SPM concentration at 0.2 mab $(x)$ and at 2 mab (y) during long-term measurements at MOW1 and the Kwintebank. The correlation is calculated after log transformation of

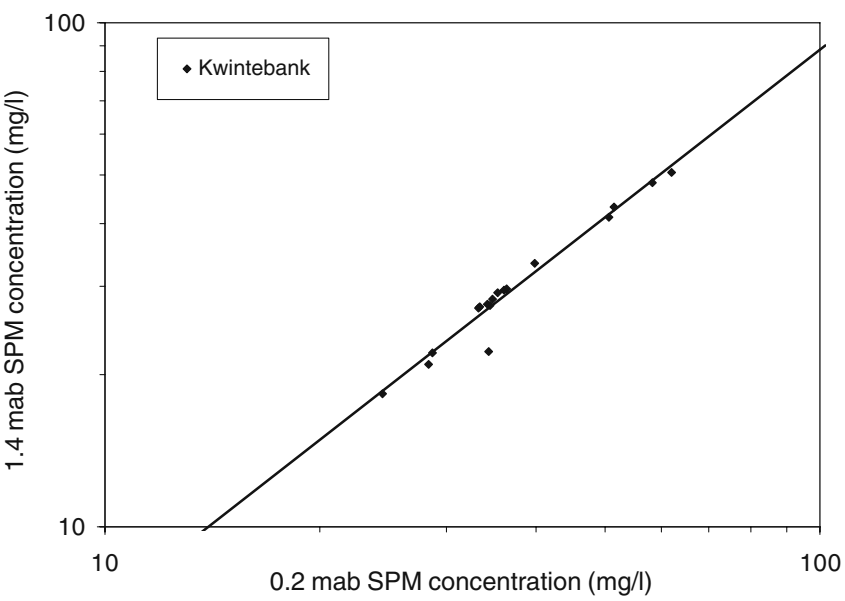

the data and has a $R^{2}=0.69$ (MOW1-1, 2, 3, 5, 6, 7) and $R^{2}=0.33$ (MOW1-4, 8) 


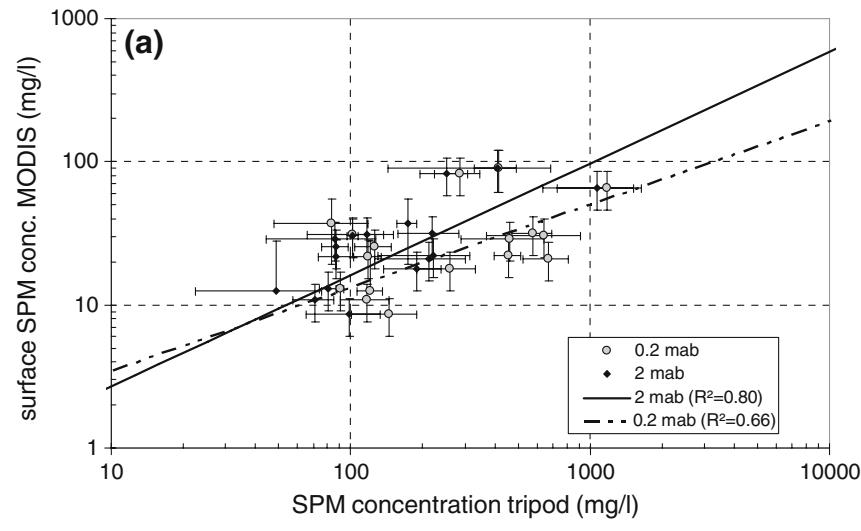

Fig. 7 Correlation between SPM concentration from tripod data at 2 and $0.2 \mathrm{mab}$ and the surface (a) and depth-corrected (b) MODIS SPM concentration during matchups. The correlations are calculated after $\log$ transformation of the data and take into account the uncertainties

very similar for the data collected during periods with $U_{\mathrm{w}}>0.03 \mathrm{~m} \mathrm{~s}^{-1}$ and $U_{\mathrm{w}}<0.3 \mathrm{~m} \mathrm{~s}^{-1}$. The mean SPM concentration at MOW1 increases from $145 \mathrm{mg} \mathrm{l}^{-1}\left(U_{\mathrm{w}}<\right.$ $\left.0.03 \mathrm{~m} \mathrm{~s}^{-1}\right)$ to $338 \mathrm{mg} \mathrm{l}^{-1}\left(U_{\mathrm{w}}>0.5 \mathrm{~m} \mathrm{~s}^{-1}\right)$ at $2 \mathrm{mab}$ and from $263 \mathrm{mg} \mathrm{l}^{-1}\left(U_{\mathrm{w}}<0.03 \mathrm{~m} \mathrm{~s}^{-1}\right)$ to $617 \mathrm{mg} \mathrm{l}^{-1}\left(U_{\mathrm{w}}>\right.$ $0.5 \mathrm{~m} \mathrm{~s}^{-1}$ ) at $0.2 \mathrm{mab}$; this confirms the nonlinear behaviour
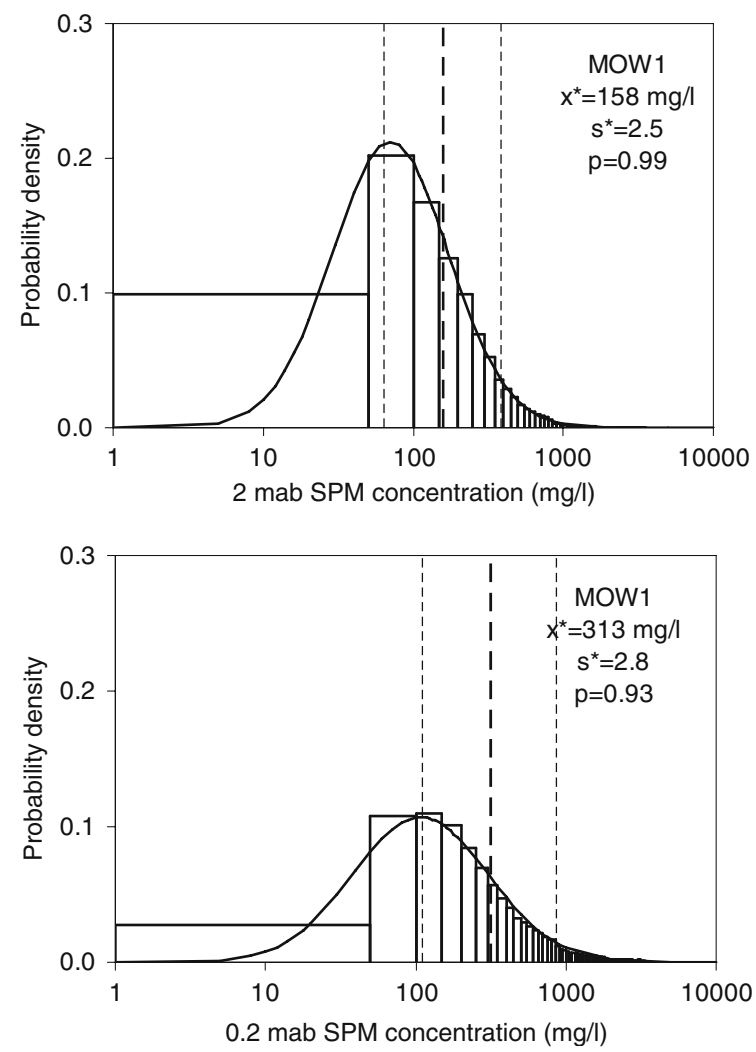

Fig. 8 Probability density distribution of long-term SPM concentration data at 2 and $0.2 \mathrm{mab}$ and the corresponding log-normal probability density functions. The data at MOW1 are binned in classes of $50 \mathrm{mg} \mathrm{l}^{-1}$ and those from the Kwintebank in classes of $5 \mathrm{mg}^{-1}$. The data fit the

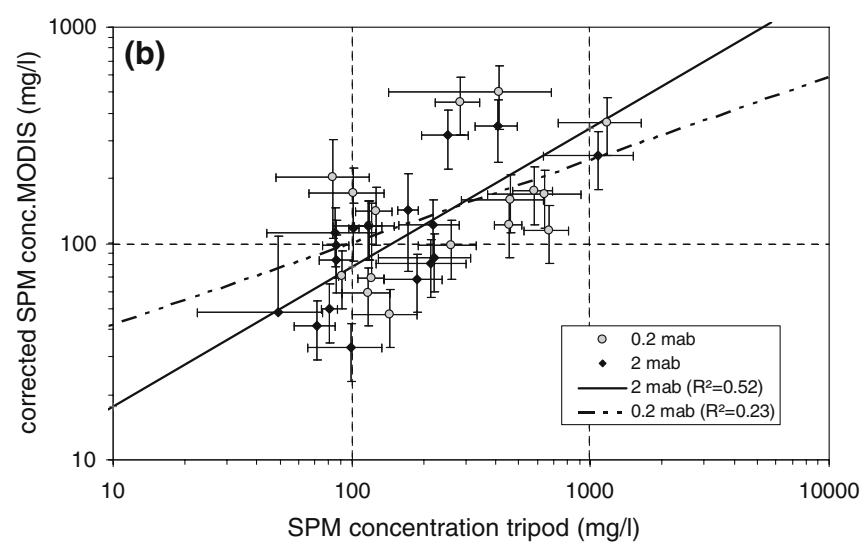

of the measurements, as indicated by the error bars. These consist of the bulk mean error (see Section 3) for MODIS and of the standard deviation of the in situ data falling within $1 \mathrm{~h}$ of satellite overpass

of the system. The SPM concentration distribution from the tidal cycle data at 2 mab corresponds well-but still with significant differences - with the good weather tripod data $\left(U_{\mathrm{w}}<0.03 \mathrm{~m} \mathrm{~s}^{-1} ; x^{*}=81\right.$ versus $\left.145 \mathrm{mg} \mathrm{l}^{-1}\right)$. Similar results are found for the 0.2-mab tidal cycle data and the good weather tripod data (93 versus $263 \mathrm{mg} \mathrm{l}^{-1}$ ).
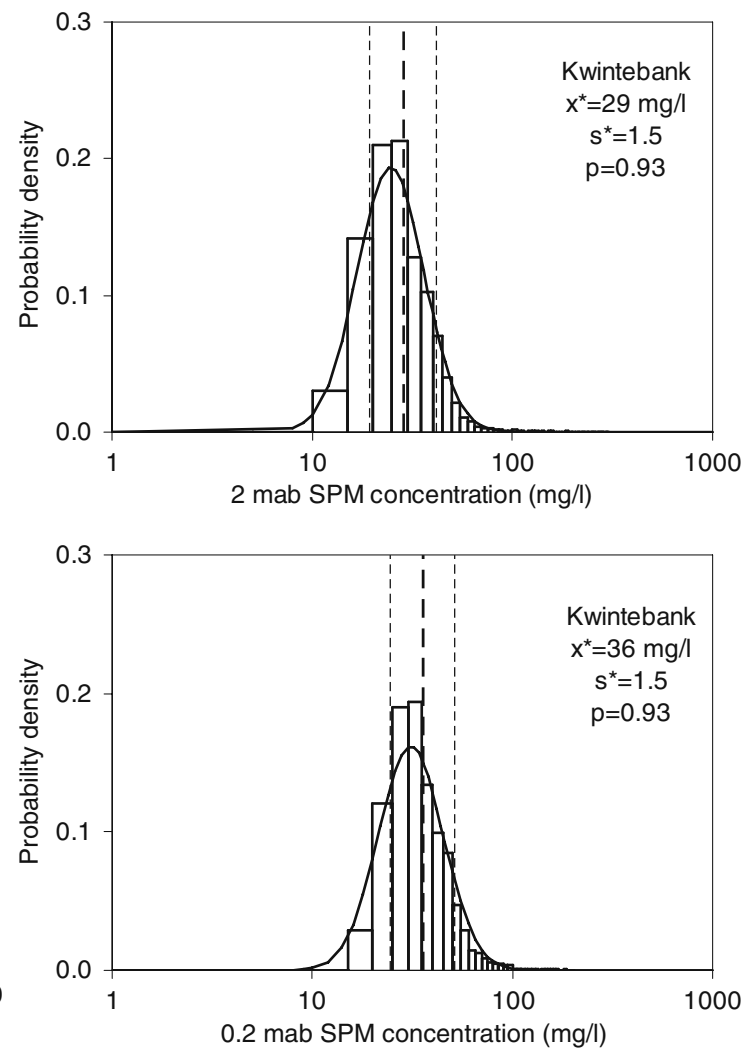

log-normal distribution with a $X^{2}$ test probability of $p>0.9$. The dashed lines correspond to the geometric mean $x^{*}$ times/over the multiplicative standard deviation $s^{*}$ 

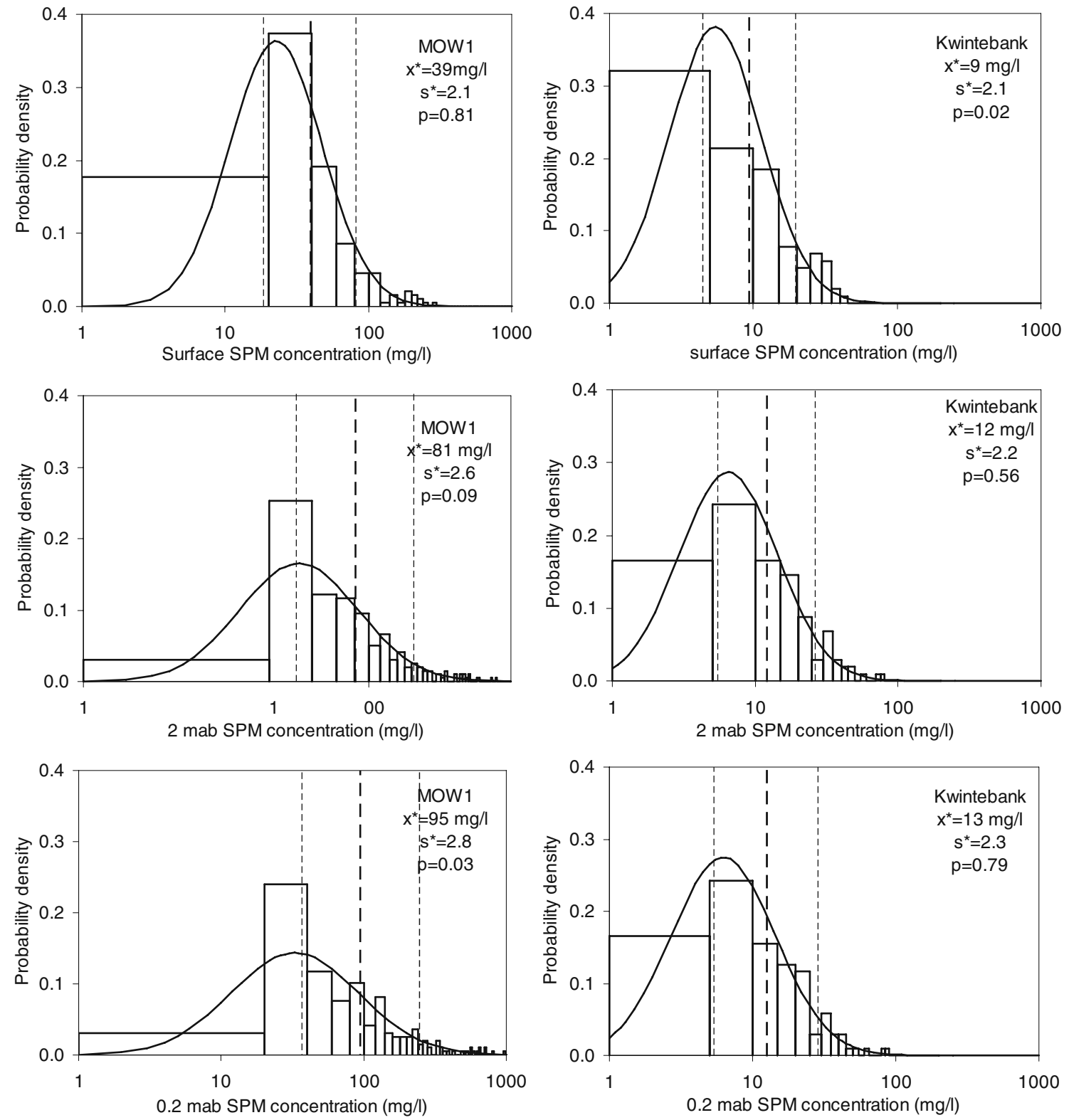

Fig. 9 Probability density distribution of tidal cycle SPM concentrations at surface, 2 and 0.2 mab derived from fitted profiles and the corresponding log-normal probability density functions. The data at MOW1 are binned in classes of $20 \mathrm{mg}^{-1}$ and those from the Kwintebank in classes of $5 \mathrm{mg} 1^{-1}$. The data fit the log-normal

\subsection{Surface correction of tripod data}

By extrapolating the Kwintebank and MOW1 tripod data towards the surface, the three datasets (tripod, tidal cycle and MODIS) can be compared to each other. The surface extrapolation has been calculated for the 2- and 0.2-mab tripod data using the relations obtained from all profiles in Table 3. This results in slightly higher surface values from $0.2 \mathrm{mab}$ (Table 4). The difference between satellites, tidal cycle and tripod surface data is more significant. The lowest mean SPM concentrations are found for the satellite data (Kwintebank,

distribution with a $X^{2}$ test probability of $p>0.6$, except MOW1 2 mab, MOW1 0.2 mab and Kwintebank surface, which have a probability of $p<0.1$. The dashed lines correspond to the geometric mean $x^{*}$ times/ over the multiplicative standard deviation $s^{*}$

$6 \mathrm{mg} \mathrm{l}^{-1}$; MOW1, $23 \mathrm{mg} \mathrm{l}^{-1}$ ) and the highest for the tripod data (Kwintebank, $19 \mathrm{mg} \mathrm{l}^{-1}$; MOW1, $59 \mathrm{mg} \mathrm{l}^{-1}$ for 2-mab extrapolation).

The results show that the mean SPM concentration of the satellite data at the Kwintebank is included within 1 standard deviation of the tidal cycle data and vice versa. The tidal cycle and satellite data are not included in the tripod data within 1 standard deviation. This is possibly linked to the fact that the tripod data are restricted to March 2004 and thus not representative for a whole year (Table 1 and Fig. 2). When only winter satellite data are selected, 


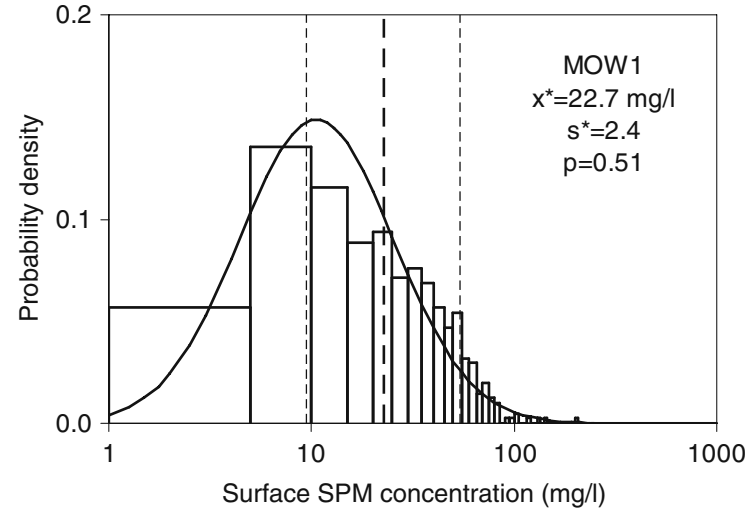

Fig. 10 Probability density distribution of MODIS surface SPM concentrations and the corresponding log-normal probability density functions. The data are binned in classes of $5 \mathrm{mg} \mathrm{l}^{-1}$ and fit the log-

then a higher mean SPM concentration of $12 \mathrm{mg} \mathrm{l}^{-1}$ is obtained, which is, however, still very low compared to the mean of tripod data. At MOW1, the mean SPM concentration from the tidal cycle dataset is included within 1 standard deviation of the mean from the tripod and the satellite datasets. The mean SPM concentrations from the tripod and satellite datasets are not included within 1 standard deviation.

\section{Discussion}

The results of standard statistic tests show that the tidal cycle, tripod and MODIS datasets have different distributions and that they represent a different subpopulation of the whole SPM concentrations population. Below, some points are discussed in more detail to identify the differ-

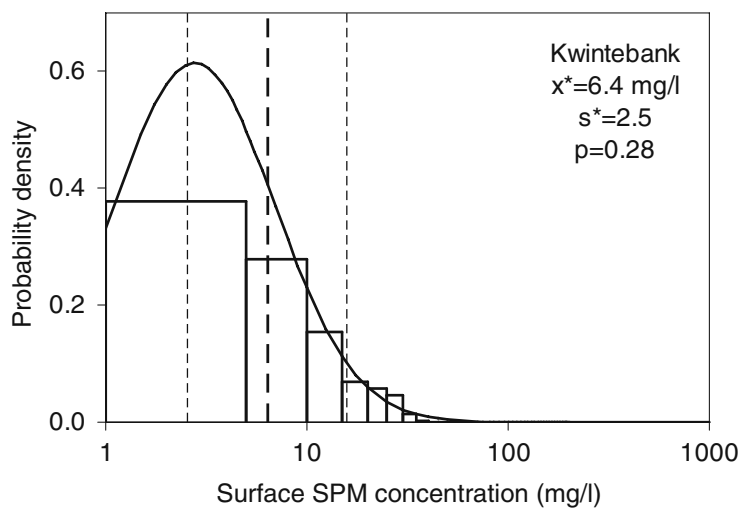

normal distribution with a $X^{2}$ test probability of $p=0.51$ (MOW1) and $p=0.28$ (Kwintebank). The dashed lines correspond to the geometric mean $x^{*}$ times/over the multiplicative standard deviation $s^{*}$

ences between the sampling methods, to analyse if and to what extent tidal cycle and satellite data can be regarded a representative subsample of the tripod data and to present the effect of measuring uncertainties on the datasets. This analysis is carried out only for the MOW1 data because these data can be considered as representative of seasons and extreme events.

\subsection{Representativeness of SPM concentration data}

A first characterisation of the SPM concentration as a function of sea states characterised by the wave orbital velocity has been carried out (see above). The surface correction of the tripod data sampled during different sea states are presented in Table 5. The surface-extrapolated values from $2 \mathrm{mab}$ vary between $91 \mathrm{mg} \mathrm{l}^{-1}\left(U_{\mathrm{w}}>0.5 \mathrm{~m} \mathrm{~s}^{-1}\right)$, $59 \mathrm{mg}^{-1}$ (all data) and $56 \mathrm{mg} \mathrm{l}^{-1}\left(U_{\mathrm{w}}<0.03 \mathrm{~m} \mathrm{~s}^{-1}\right)$ and are
Table 4 Geometric mean SPM concentration $\left(x^{*}\right)$ of tidal cycle (TC), tripod and MODIS satellite measurements at MOW1 and from the Kwintebank

The surface values for tripod data have been obtained by extrapolating the 0.2 - and the 2-mab data using the relations of Table 3. Also shown is the $X^{2}$ test probability $(p)$ of the distributions compared with a log-normal one

$s *$ multiplicative standard deviation

\begin{tabular}{llllll}
\hline Location & Method & Depth & $x^{*}(\mathrm{mg} / \mathrm{l})$ & $s^{*}$ & $p$ \\
\hline MOW1 & MODIS & Surface & 23 & 2.4 & 0.51 \\
& TC & Surface & 39 & 2.1 & 0.81 \\
& TC & 2 mab & 81 & 2.6 & 0.09 \\
& TC & 0.2 mab & 93 & 2.8 & 0.02 \\
& Tripod & Surface & $59(2 \mathrm{mab})$ & $1.7(2 \mathrm{mab})$ & $0.97(2 \mathrm{mab})$ \\
& & & $1.6(0.2 \mathrm{mab})$ & $0.11(0.2 \mathrm{mab})$ \\
& Tripod & 2 mab & $174 \mathrm{mab})$ & 2.5 & 0.99 \\
& Tripod & 0.2 mab & 326 & 2.8 & 0.99 \\
& MODIS & Surface & 6 & 2.5 & 0.28 \\
& TC & Surface & 9 & 2.1 & 0.02 \\
& TC & 2 mab & 12 & 2.2 & 0.56 \\
& TC & 0.2 mab & 13 & 2.3 & 0.79 \\
& Tripod & Surface & $19(2 \mathrm{mab})$ & $1.4(\mathrm{both})$ & 0.00 (both) \\
& & $23(0.2 \mathrm{mab})$ & & 0.93 \\
& Tripod & 2 mab & 29 & 1.5 & 0.93 \\
\hline
\end{tabular}


Table 5 Geometric mean SPM concentration $\left(x^{*}\right)$ at MOW1 for different wave conditions

\begin{tabular}{lccccccccccccc}
\hline & \multicolumn{10}{c}{0.2 mab } \\
\hline$U_{\mathrm{w}}\left(\mathrm{m} \mathrm{s}^{-1}\right)$ & $>0.5$ & $>0.3$ & $>0.03$ & All & $<0.3$ & $<0.03$ & $>0.5$ & $>0.3$ & $>0.03$ & All & $<0.3$ & $<0.03$ \\
$x^{*}\left(\mathrm{~m} \mathrm{l} \mathrm{l}^{-1}\right)$ & 338 & 278 & 176 & 178 & 155 & 145 & 617 & 513 & 390 & 313 & 308 & 263 \\
$s^{*}$ & 1.6 & 1.8 & 2.5 & 2.0 & 2.5 & 2.4 & 1.9 & 2.0 & 2.8 & 2.8 & 2.8 & 2.8 \\
$p$ & 0.77 & 0.95 & 0.99 & 0.91 & 0.99 & 0.99 & 0.99 & 1.00 & 1.00 & 0.93 & 0.91 & 0.96 \\
Surface $x^{*}\left(\mathrm{mg} \mathrm{l}^{-1}\right)$ & 91 & 82 & 63 & 59 & 58 & 56 & 92 & 87 & 75 & 68 & 67 & 63 \\
$s^{*}$ & 1.3 & 1.4 & 1.7 & 1.7 & 1.7 & 1.6 & 1.3 & 1.3 & 1.6 & 1.6 & 1.6 & 1.6 \\
$p$ & 0.00 & 0.00 & 0.95 & 0.11 & 0.97 & 0.87 & 0.00 & 0.00 & 0.01 & 0.97 & 0.14 & 0.35 \\
\hline
\end{tabular}

Also shown is the $X^{2}$ test probability ( $p$ ) of the distributions compared with a log-normal one. The distributions are from long-term measurements at MOW1 and have been selected according to wave orbital velocity $\left(U_{\mathrm{w}}\right)$ conditions

$s^{*}$ multiplicative standard deviation, surface $x^{*}$ surface-corrected $x^{*}$ using relations for all profiles from Table 3

still significantly higher than the tidal cycle and satellite data (Table 4). This result underlines that near-bed SPM concentration dynamics and the formation of fluid mud or HCBS layers are partially uncoupled from processes higher up in the water column and possibly point to the fact that 18 tidal cycle measurements or 460 satellite images are not representative of the good weather population at MOW1.

\subsection{Sampling methods}

Sampling is regarded as a statistical practice to select individual SPM concentration observations, which can give some understanding of the SPM concentration population at a specific location or in a whole area. A common goal of these measurements should be to collect a representative subset of this population, which is used to generalise findings back to a population, within the limits of random errors. When dealing with time-dependent, particularly harmonically varying processes, such as SPM concentration, then one should be aware of the number of data (tidal cycle, satellite) which have to be available before being representative as subset of the population. It is therefore essential to have knowledge on how representative a sampling method is and to deal with the bias induced by it. Differences between the datasets may be due to the fact that in situ and remote sensing measuring techniques are based on different sampling methods.

Satellites can be seen as random samplers biased towards good weather conditions as they represent only the cloud-free data, but also to non-satellite-saturating data which occur at high SPM concentration levels. Tidal cycle measurements from a vessel and long-term measurements (stand-alone structures) can be described as an eventbased sampling method, characterised by a random start and then proceeding with the collection of data during at least one tidal cycle. Clustering the sampling during one tide identifies the most significant SPM concentration variation.
A more objective approach is to apply sampling schemes to the full set of data and to base the analysis on the subsamples out of this population (Schleppi et al. 2006). If we assume that the tripod data from MOW1 are a good representation of the natural variability during a year, then we can randomly sample these data with similar sampling methods as satellites or tidal cycle measurements. To this end, we can study how low-frequency sampling over time affects the statistical mean and standard deviation. The satellite images are mainly situated during periods of low wind (Fettweis et al. 2007); therefore, significant wave heights smaller than $0.5 \mathrm{~m}$ have been used as proxy for cloud-free conditions. Three sampling schemes for satellite data have been adopted; scheme 1 consists of 60 random data, scheme 2 of 60 random data with $H_{\mathrm{s}}<0.44 \mathrm{~m}$ and scheme 3 of 60 random data with sampling time between 13 and $14 \mathrm{~h}$ and $H_{\mathrm{s}}<0.44 \mathrm{~m}$. A significant wave height of $0.44 \mathrm{~m}$ corresponds to the median significant wave height during satellite overpass (see above). The tidal cycle sampling scheme consists of six random sampling events at significant wave heights smaller than $1.5 \mathrm{~m}$ with each 13 successive data every hour (total 78 data) for each event. Each sampling scheme has been repeated ten times in order to assess variability due to the random number generator (Table 6).

The satellite sampling scheme 1 gives very similar mean SPM concentrations (182 versus $178 \mathrm{mg} \mathrm{l}^{-1}$ at 2 mab and 347 versus $313 \mathrm{mg}^{-1}$ at $0.2 \mathrm{mab}$ ) and multiplicative standard deviations as for all the tripod data, whereas satellite sampling scheme 2 decreases the mean SPM concentration $\left(158 \mathrm{mg} \mathrm{l}^{-1}\right.$ at $2 \mathrm{mab}$ and $258 \mathrm{mg} \mathrm{l}^{-1}$ at $0.2 \mathrm{mab}$ ) and multiplicative standard deviations (Table 6). The results of satellite sampling scheme 2 are similar to the mean SPM concentrations of subsets of tripod data with $U_{\mathrm{w}}<0.03 \mathrm{~m} \mathrm{~s}^{-1}$ (158 versus $145 \mathrm{mg} \mathrm{l}^{-1}$ at $2 \mathrm{mab}$ and 258 versus $263 \mathrm{mg}^{-1}$ at $0.2 \mathrm{mab}$ ). From these results, one could conclude that 60 samples are representative of the mean and multiplicative standard deviation of the whole 
Table 6 Geometric mean SPM concentration $\left(x^{*}\right)$ obtained when applying similar sampling schemes as satellites and tidal cycles to the long-term tripod measurements at MOW1 (see Section 5)

\begin{tabular}{|c|c|c|c|c|c|c|c|c|}
\hline \multirow[t]{2}{*}{ Sampling scheme } & \multicolumn{4}{|l|}{$2 \mathrm{mab}$} & \multicolumn{4}{|l|}{$0.2 \mathrm{mab}$} \\
\hline & Sat 1 & Sat 2 & Sat 3 & $\mathrm{TC}$ & Sat 1 & Sat 2 & Sat 3 & $\mathrm{TC}$ \\
\hline$x^{*}\left(\mathrm{mg} \mathrm{l}^{-1}\right) \pm \mathrm{stdv}$ & $182 \pm 12$ & $158 \pm 13$ & $153 \pm 19$ & $183 \pm 63$ & $347 \pm 42$ & $258 \pm 23$ & $236 \pm 31$ & $284 \pm 105$ \\
\hline$s^{*}$ & 2.6 & 2.2 & 2.2 & 2.1 & 2.7 & 2.4 & 2.5 & 2.3 \\
\hline$p$ & 0.49 & 0.62 & 0.45 & 0.23 & 0.78 & 0.64 & 0.59 & 0.35 \\
\hline Surface $x^{*}\left(\mathrm{mg}^{-1}\right)$ & $64 \pm 2$ & $59 \pm 3$ & $58 \pm 4$ & $64 \pm 12$ & $71 \pm 3$ & $62 \pm 3$ & $59 \pm 3$ & $64 \pm 11$ \\
\hline$s^{*}$ & 1.7 & 1.6 & 1.5 & 1.5 & 1.6 & 1.5 & 1.5 & 1.4 \\
\hline$p$ & 0.43 & 0.28 & 0.27 & 0.38 & 0.14 & 0.28 & 0.32 & 0.08 \\
\hline
\end{tabular}

Also shown is the $X^{2}$ test probability ( $p$ ) of the distributions compared with a log-normal one. Each sampling scheme has been repeated ten times to assess variability due to random number generation

Sat satellite sampling scheme, $T C$ tidal cycle sampling scheme, $x^{*} \pm s t d v$ mean \pm standard deviation, $s^{*}$ multiplicative standard deviation, surface $x^{*}$ surface-corrected $x^{*}$ using relation for all profiles from Table 3

population and that applying satellite sampling scheme 2 lowers the mean SPM concentration. The latter is mainly induced by the 'good weather' data, but also the time of sampling has an effect as shown by satellite sampling scheme 3, which decreases again the mean of SPM concentrations (Table 6). This conclusion is further strengthened by the fact that repeating the sampling scheme does not result in a higher standard deviation. The generally better weather conditions during spring and summer result in a higher frequency of spring and summer data $(60 \%)$ with respect to autumn and winter data (40\%) using satellite sampling schemes 2 and 3 and agree well with the distribution over seasons of the available satellite images.

With the tidal cycle sampling scheme, a similar mean SPM concentration as that from the subset of tripod data $\left(H_{\mathrm{s}}<0.3 \mathrm{~m} \mathrm{~s}^{-1}\right)$ is obtained ( 185 versus $155 \mathrm{mg}^{-1}$ at $2 \mathrm{mab}$ and 284 versus $308 \mathrm{mg} \mathrm{l}^{-1}$ at $0.2 \mathrm{mab}$ ). The confidence limits due to random number generation expressed as relative standard deviation is about $33 \%$, which is higher than with the satellite sampling schemes, although the total number of samples is not substantially different ( 78 versus 60 ). The high variability during a tidal cycle is thus maintained and reflected by the mean data of the tidal cycle sampling scheme, whereas it is lost when using satellite sampling schemes (Fettweis et al. 2007).

\subsection{Uncertainties associated with sampling}

Surface correction of the sub-dataset of SPM concentrations obtained by sampling the tripod data using similar sampling schemes as satellites (scheme 3 ) and tidal cycle measurements still shows differences with the satellite (58 versus $23 \mathrm{mg} \mathrm{l}^{-1}$ ) and tidal cycle (64 versus $39 \mathrm{mg} \mathrm{l}^{-1}$ ) SPM concentrations. To obtain an agreement within 1 standard deviation between surface-corrected SPM concentrations from satellite scheme $3\left(x^{*}=30 \mathrm{mg}^{-1}, s^{*}=1.5\right)$, tidal cycle scheme $\left(x^{*}=32 \mathrm{mg} \mathrm{l^{-1 }}, s^{*}=1.5\right)$ and satellite data $\left(x^{*}=\right.$ $23 \mathrm{mg} \mathrm{l}^{-1}, s^{*}=2.4$ ), the correction factor for type 2 profiles have to be used. These profiles have a probability of occurrence of $25 \%$ at MOW1. This points possibly to an underestimation of type 2 profiles during the tidal cycle measurements, but is probably also caused by the limitation of the remote sensing data to lower SPM concentrations due to saturation. Furthermore, the approximation of the vertical SPM concentration profile by a simple log function, which does not take into account settling and vertical mixing effects, is therefore-although a high linear correlation coefficient exists between the measured and the fitted values (MOW1: $r=0.77$; Kwintebank: $r=0.98$ ) - probably not accurate for type 2 profiles near the sea bed. The very high SPM concentrations $\left(>3.6 \mathrm{~g} \mathrm{l}^{-1}\right.$ at $0.2 \mathrm{mab}$ and $2.6 \mathrm{~g} \mathrm{l}^{-1}$ at $2 \mathrm{mab}$ ) found in the tripod data at MOW1, but never measured by satellites or during tidal cycle measurements (maximum $1 \mathrm{~g} \mathrm{l}^{-1}$ during 2006/06, see Table 2), confirm the major impact of near-bed dynamics induced by high wave heights on the SPM concentration in a coastal area. The formation of HCBS in wave-dominated areas and the difference with SPM dynamics in the rest of the water column are well documented (de Wit and Kranenburg 1997; Li and Mehta 2000; Winterwerp 2006).

\section{Conclusions}

This paper shows that SPM concentration derived from three different methods for measuring SPM concentration (tripod at fixed location, tidal cycle from a vessel and satellite) results in different frequency distributions. The analysis was applied to two locations: MOW1 situated in a high-turbidity area and Kwintebank in low-turbidity waters. In order to compare near-bed SPM concentrations from tripod with surface concentration from satellite, correction 
factors have been constructed based on vertical SPM concentration profiles measured during tidal cycles. The differences between the datasets are related to the different meteorological conditions during measurements; to nearbed SPM concentration dynamics, which are partially uncoupled from processes higher up in the water column; to the sampling methods or schemes used to collect the data; to the method of surface correction assuming a logarithmic profiles near the bed; and to measuring uncertainties. The main conclusions are:

1. Due to the time and spatial variability of SPM concentration in coastal high-turbidity areas, greater sampling efforts are necessary as compared to offshore systems with low SPM concentration.

2. Satellite, tidal cycle and tripod SPM concentrations are very similar at the Kwintebank (20-m depth, situated $20 \mathrm{~km}$ offshore at the edge of the coastal high-turbidity area) with respect to uncertainties of SPM concentration measurements in low-turbidity areas.

3. Satellites or low-frequent tidal cycle measurements cannot replace long-term continuous measurements in high turbidity areas, which include all sea state conditions. They consist of a subset of the population biased towards good weather condition or springsummer seasons (satellite). Sediment transport based on these data will thus always underestimate reality.

4. The mean SPM concentration calculated with 60 randomised (unbiased) sampling occasions per year is representative of the mean SPM concentration of the whole population. When an emulated satellite sampling scheme, using a specific criterion for significant wave height $\left(H_{\mathrm{s}}<0.44 \mathrm{~m}\right)$ and sampling time (during satellite overpass), is applied, then the 60 samples represent the good weather SPM concentration. The mean SPM concentration calculated from six randomly distributed tidal cycle measurements per year using a $H_{\mathrm{s}}<1.5 \mathrm{~m}$ as criterion gives a similar mean SPM concentration as the whole population. The high SPM concentration variability during a tidal cycle is maintained, whereas it is lost when using satellite sampling schemes.

5. The mean SPM concentrations derived from satellite datasets are included within 1 standard deviation of the mean from the tidal cycle datasets at both locations. This points out the good agreement between the distributions of the two datasets. SPM concentrations from tripod, extrapolated to the water surface and subsampled following the satellites sampling scheme, have a mean significantly higher than the mean of satellite surface SPM concentrations. The reasons are due to uncertainties in the calculation of vertical profiles used to achieve the extrapolation and to the fact that probably a filtering of high SPM concen- trations $\left(>200 \mathrm{mg} \mathrm{l}^{-1}\right)$ occurred where the visible band saturates.

Acknowledgement This study was partly funded by the Maritime Access Division of the Ministry of the Flemish Community in the framework of the MOMO project and by the Belgian Science Policy within the framework of the QUEST4D (SD/NS/06A) and BELCOLOUR-2 (SR/00/104) projects. G. Dumon (Coastal Service, Ministry of the Flemish Community) made available wave measurement data. We want to acknowledge the crew of the RV Belgica, Zeearend and Zeehond for their skilful mooring and recuperation of the tripod. The measurements would not have been possible without technical assistance of A. Pollentier, J.-P. De Blauwe and J. Backers (measuring service of MUMM, Oostende). V. Van Lancker, G.P. Fettweis and H. Nuszkowski are acknowledged for their valuable suggestions and comments.

Open Access This article is distributed under the terms of the Creative Commons Attribution Noncommercial License which permits any noncommercial use, distribution, and reproduction in any medium, provided the original author(s) and source are credited.

\section{References}

Badewien TH, Zimmer E, Bartholomä A, Reuter R (2009) Towards continuous long-term measurements of suspended particulate matter (SPM) in turbid coastal waters. Ocean Dyn 59:227-238. doi:10.1007/s10236-009-0183-8

Bartholomä A, Kubicki A, Badewien TH, Flemming BW (2009) Suspended sediment transport in the German Wadden Seaseasonal variations and extreme events. Ocean Dyn 59:213-255. doi:10.1007/s10236-009-0193-6

Blewett J, Huntley DA (1998) Measurement of suspended sediment transport processes in shallow water off the Holderness Coast, UK. Mar Pollut Bull 37:134-143

Bograd SJ, Rabinovich AB, Thomson RE, Eert AJ (1999) On sampling strategies and interpolation schemes for satellitetracked drifters. J Atmos Ocean Technol 16:893-904

Bowers DG, Boudjelas S, Harker GEL (1998) The distribution of fine suspended sediments in the surface waters of the Irish Sea and its relation to tidal stirring. Int J Remote Sens 19:2789-2805

Bowers DG, Gaffney S, White M, Bowyer P (2002) Turbidity in the southern Irish Sea. Cont Shelf Res 22:2115-2126

Buijsman MC, Ridderinkhof H (2007) Long-term ferry-ADCP observations of tidal currents in the Marsdiep inlet. J Sea Res 57:237-256. doi:10.1016/j.seares.2006.11.004

Cacchione DA, Drake DE, Kayen RW, Sternberg RW, Kineke GC, Tate GB (1995) Measurements in the bottom boundary subaqueous delta. Mar Geol 125:235-257

Caeiro S, Painho M, Goovaerts P, Costa H, Sousa S (2003) Spatial sampling design for sediment quality assessment in estuaries. Environ Monit Softw 18:853-859. doi:10.1016/S1364-8152(03)00103-8

de Wit PJ, Kranenburg C (1997) The wave-induced liquefaction of cohesive sediment beds. Estuar Coast Shelf Sci 45:261-271

Doxaran D, Froidefond J-M, Lavender S, Castaing P (2002) Spectral signatures of highly turbid waters. Application with SPOT data to quantify suspended particulate matter concentrations. Remote Sens Environ 81:149-161

Doxaran D, Froidefond J-M, Castaing P, Babin M (2009) Dynamics of the turbidity maximum zone in a macrotidal estuary (the Gironde, France): observations from field and MODIS satellite data. Estuar Coast Shelf Sci 81:321-332. doi:10.1016/j.ecss.2008.11.013 
Eleveld MA, Pasterkamp R, van der Woerd HJ, Pietrzak JD (2008) Remotely sensed seasonality in the spatial distribution of sea-surface suspended particulate matter in the southern North Sea. Estuar Coast Shelf Sci 80:103-113. doi:10.1016/j.ecss.2008.07.015

Fettweis M (2008) Uncertainty of excess density and settling velocity of mud derived from in situ measurements. Estuar Coast Shelf Sci 78:426-436. doi:10.1016/j.ecss.2008.01.007

Fettweis M, Nechad B, Van den Eynde D (2007) An estimate of the suspended particulate matter (SPM) transport in the southern North Sea using SeaWiFS images, in situ measurements and numerical model results. Cont Shelf Res 27:1568-1583. doi:10.1016/j. csr.2007.01.017

Fettweis M, Francken F, Van den Eynde D, Verwaest T, Janssens J, Van Lancker V (2010) Storm influence on SPM concentrations in a coastal turbidity maximum area with high anthropogenic impact (southern North Sea). Cont Shelf Res. doi:10.1016/j.csr.2010.05.001

Hall P, Davies AM (2005) The influence of sampling frequency, nonlinear interaction, and frictional effects upon the accuracy of the harmonic analysis of tidal simulations. Appl Math Model 29:533-552. doi:10.1016/j.apm.2004.09.015

Hoitink AJF, Hoekstra P (2005) Observations of suspended sediment from ADCP and OBS measurements in a mud-dominated environment. Coast Eng 52:103-118. doi:10.1016/j.coastaleng.2004.09.005

Li Y, Mehta AJ (2000) Fluid mud in the wave-dominated environment revisited. In: McAnally WH, Mehta AJ (eds) Coastal and estuarine fine sediment dynamics. Proceedings in Marine Science 3. Elsevier, Amsterdam, pp 79-93

Li MZ, Amos CL, Heffler DE (1997) Boundary layer dynamics and sediment transport under storm and non-storm conditions on the Scotian Shelf. Mar Geol 141:157-181

Limpert E, Stahel W, Abbt M (2001) Log-normal distributions across the sciences: keys and clues. Bioscience 51:341-352

Lynch DR, McGillicuddy DJ, Werner FE (2009) Skill assessment for coupled biological/physical models of marine systems. J Mar Syst 76:1-3. doi:10.1016/j.jmarsys.2008.05.002

Ma Y, Wright LD, Friedrichs CT (2008) Observations of sediment transport on the continental shelf off the mouth of the Waiapu River, New Zealand: evidence for current-supported gravity flows. Cont Shelf Res 28:516-532. doi:10.1016/j.csr.2007.11.001

Nechad B, De Cauwer V, Park Y, Ruddick KG (2003) Suspended particulate matter (SPM) mapping from MERIS imagery. Calibration of a regional algorithm for the Belgian coastal waters. ESA MERIS user workshop, 10-13th November 2003

Nechad B, Ruddick KG, Park Y (2010) Calibration and validation of a generic multisensor algorithm for mapping of total suspended matter in turbid waters. Remote Sens Environ 114:854-866. doi:10.1016/j.rse.2009.11.022

Ogston AS, Cacchione DA, Sternberg RW, Kineke GC (2000) Observations of storm and river-flood driven sediment transport on the northern California continental shelf. Cont Shelf Res 20:2141-2162

Pepper DA, Stone GW (2004) Hydrodynamic and sedimentary responses to two contrasting winter storms on the inner shelf of the northern Gulf of Mexico. Mar Geol 210:43-62. doi:10.1016/ j.margeo.2004.05.004

Ruddick KG, Ovidio F, Rijkeboer M (2000) Atmospheric correction of SeaWiFS imagery for turbid coastal and inland waters. Appl Opt 39:897-912

Ruhl CA, Schoelhammer DH, Stumpf RP, Lindsay CL (2001) Combined use of remote sensing and continuous monitoring to analyse the variability of suspended-sediment concentrations in San Francisco Bay, California. Estuar Coast Shelf Sci 53:801812. doi:10.1006/ecss. 2000.0730

Schleppi P, Waldner PA, Fritschi B (2006) Accuracy and precision of different sampling strategies and flux integration methods for runoff water: comparisons based on measurements of the electrical conductivity. Hydrol Process 20:395-410. doi:10.1002/ hyp. 6057

Shindo K, Otsuki A (1999) Establishment of a sampling strategy for the use of blue mussels as an indicator of organotin contamination in the coastal environment. J Environ Monit 1:243-250

Soulsby R (1997) Dynamics of marine sands. Thomas Telford, London, $\mathrm{p} 249$

Stow CA, Joliff J, McGillicuddy DJ, Doney SC, Allen JI, Friederichs MAM, Rose KA, Wallhead P (2009) Skill assessment for coupled biological/physical models of marine systems. J Mar Syst 76:4-15. doi:10.1016/j.jmarsys.2008.03.011

Van den Eynde D, Nechad B, Fettweis M, Francken F (2007) SPM dynamics in the southern North Sea derived from SeaWifs imagery, in situ measurements and numerical modelling. In: Maa JP-Y, Sanford LP, Schoelhammer DH (eds) Estuarine and coastal fine sediment dynamics. Proceedings in Marine Science 8. Elsevier, Amsterdam, pp 299-311

Wang M, Son S, Shi W (2009) Evaluation of MODIS SWIR and NIRSWIR atmospheric correction algorithms using SeaBASS data. Remote Sens Environ 113:635-644. doi:10.1016/j.rse.2008.11.005

Werdell PJ, Bailey SW, Franz BA, Harding LW, Feldman GC, McClain CR (2009) Regional and seasonal variability of chlorophyll-a in Chesapeake Bay as observed by SeaWiFS and MODIS-Aqua. Remote Sens Environ 113:1319-1330. doi:10.1016/ j.rse.2009.02.012

Winterwerp J (2006) Stratification effects by fine suspended sediment at low, medium and very high concentrations. J Geophys Res 111:C05012. doi:10.1029/2005JC003019

Zawada DG, Hu C, Clayton T, Chen Z, Brock JC, Muller-Karger FE (2007) Remote sensing of particle backscattering in Chesapeake Bay: a 6-year SeaWiFS retrospective view. Estuar Coast Shelf Sci 73:792-806. doi:10.1016/j.ecss.2007.03.005 